Artikel Penelitian

\title{
Hubungan Tingkat Pengetahuan Dan Komunikasi Keluarga Dengan Interaksi Sosial Pada Remaja
}

\section{Mona Yolanda, Rani Agustia}

Program Studi S-1 Keperawatan STIKes Nan Tongga Lubuk Alung, Sumatera Barat Email: monayolanda99843@gmail.com

\begin{abstract}
Abstrak: Remaja (adolescence) menurut Hurlock didefinisikan sebagai masa peralihan dari masa kanak - kanak ke masa dewasa, rentangan usia antara 13 tahun sampai 21 tahun. Laporan "United Nations Congress on the Prevention of Crime and the Treatment of Offenders" bertemu di london menyatakan meningkatnya jumlah juvenile delinquency (kejahatan anak remaja) dunia, dalam kualitas kejahatan dan peningkatan dalam kegarangan serta kebingisannya yang lebih banyak dilakukan dalam aksi kelompok daripada tindakan kejahatan individ. Penelitian ini bertujuan untuk mengetahui hubungan pengetahuan dan komunikasi keluarga dengan interaksi social remaja kelas I dan II di SMPN 2 Lubuk Alung. Jenis penelitian deskriptif analitik menggunakan desaincross sectional study. Waktu penelitian dari Mei - Juni 2019 di SMPN 2 LubukAlung. Jumlah populasi yaitu 134 dalam tahun 2018. Sampel sebanyak73 responden. Hasil penelitian didapatkan bahwa $54,8 \%$ orang remaja berpengetahuan rendah, 50,7\% orang remaja memiliki komunikasi keluarga yang kurang baik dalam berinteraksi sosial. Hasil uji statistik uji chi-square diketahui bahwa terdapat hubungan antara pengetahuan ( $\mathrm{p}$ value 0,000) dan komunikasi keluarga dengan interaksi sosial (p value 0,000) di SMPN 2 LubukAlung. Disarankan bagi siswa/siswi agar lebih meningkatkan komunikasi dengan keluarga dan cara berinteraksi dengan baik
\end{abstract}

\begin{abstract}
Kata kunci : Tingkat Pengetahuan, Interaksi Sosial, Komunikasi Keluarga, Remaja
Abstract: Adolescence according to Hurlock is defined as a transition from childhood to adulthood, the age range from 13 years to 21 years. The report "United Nations Congress on the Prevention of Crime and the Treatment of Offenders" meeting in London stated that the increasing number of juvenile delinquencies in the world of crime, and the quality of crime and the increase in violence and brutality were carried out in group action rather than criminal actions. individu. This study aims to determine the relationship of knowledge and family communication with the social interactions of adolescents class I and II in junior high school 2 Lubuk Alung. This type of descriptive analytic study uses a cross sectional study design. Research time from May - June 2019 at SMPN 2 LubukAlung. The population is 134 in 2018. The sample is 73 respondents. Data collection by guided interviews. The results showed that $54.8 \%$ of young people with low knowledge, $50.7 \%$ of adolescents have poor family communication in social interaction. The results of the chisquare test statistic test revealed that there was a relationship between knowledge ( $p$ value $0,000)$ and family communication with social interaction (p value 0,000) at SMPN 2 LubukAlung.It is recommended for students to be expected to further improve communication with family and how to interact well
\end{abstract}

Keywords: Knowledge; Social Interaction; Family Communication; Adolescence 


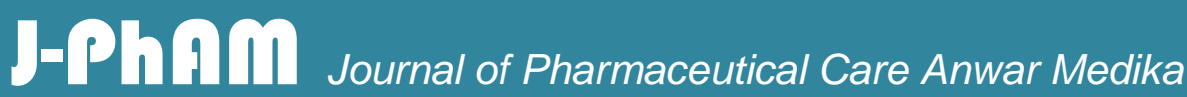

\section{Artikel Penelitian}

\section{PENDAHULUAN}

Menurut WHO tahun 2013, dalam kualitas kejahatan dan peningkatan dalam kegarangan serta kebingisannya yang lebih banyak dilakukan dalam aksi kelompok daripada tindakan kejahatan individual.Studi konflik interaksi sosial Brokks (2011), 70\% keluarga di Amerika mengalami konflik antara orang tua dan remaja yang serius, berkaitan dengan masalah remaja meninggalkan rumah, kenakalan remaja, putus sekolah, kehamilan dan pernikahan dini dan penyalahgunaan obat terlarang. Remaja Amerika akrab dengan budaya pergaulan bebas yang tidak memiliki batas yang jelas, negara pun mendukung budaya itu sehingga tidak ada hak orang tua untuk melarang aktivitas kebebasan anak-anak mereka (Santrock JW, 2009).

Penelitian Murdoch Children's Research Institute Australia tentang perilaku remaja di Australia dengan mewawancarai 4.000 pelajar berusia 12 sampai 16 tahun di victoria, diketahui 51,6\% remaja bersikap kasar, faktor utama timbulnya kelakuan buruk bagi remaja tersebut ialah problem dengan keluarga di rumah, pengaruh minuman keras dan obat terlarang (Kompas Online, 2009).

Hampir 70\% dari seluruh kasus pidana di China sekarang ini melibatkan remaja yang berusia antara 14-18 tahun. para remaja ini membentuk kelompok gang dan melakukan tindak kejahatan tanpa motif tertentu. Tindak itu termasuk pencurian, penyerangan, dan pemerkosaan. Menurut Liu, masalah ini disebabkan karena terpecahnya keluarga dan kurangnya komunikasi dalam keluarga. Shang Xiuyun, hakim di Beijing yang khusus menangani kejahatan remaja mengatakan kebijakan satu anak di China menjadi salah satu penyebab. Dengan kebanyakan keluarga hanya memiliki satu anak, maka anak ini mendapatkan tekanan yang lebih besar sekarang dibandingkan di masa lalu (Suara karya online, 2009).

Berdasarkan statistik kenakalan remaja Korea Selatan tahun ini, kejahatan dilakukan remaja tanggung ini meningkat 2,8\% dari empat tahun lalu 3,5\% pada 2009, ratarata usia 16 tahun di Negara Ginseng itu sudah terlibat kejahatan disertai tindak kekerasan seperti perampokan barang - barang berharga, jual diri, penganiayaan, dan sebagainya. 


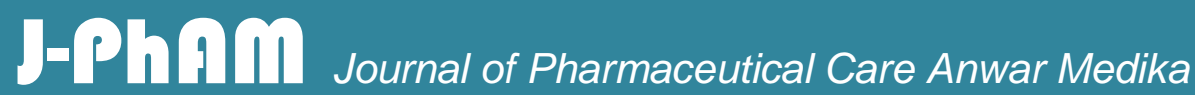

\section{Artikel Penelitian}

Gyeong dari Universitas Dongguk menyebutkan banyaknya tindak kejahatan dan kekerasan terjadi membuat perilaku mereka menjadi negatif. Remaja Korea Selatan setiap hari disuguhkan berita kriminal, Informasi dan film menjadi faktor penting membuat mereka melakukan kejahatan dengan sangat mudahnya, dan tingkat perhatian orang tua mereka menurun akibat sibuk dengan pekerjaan (Merdeka Online, 2012)

Kondisi tidak jauh berbeda dengan Indonesia, jarangnya komunikasi antar keluarga membuat remaja menentukan baik - buruknya suatu hal menurut kacamata mereka. meningkatnya insiden tindak kriminalitas di kalangan remaja melalui data kriminalitas Mabes Polri bahwa selama tahun 2015 tercatat sekitar 3.100 orang pelaku tindak pidana adalah remaja yang berusia 18 tahun atau kurang. jumlah tersebut pada tahun 2016 meningkat menjadi 4.300 remaja dan 7.200 remaja pada tahun 2017. Mayoritas atau sebesar 77,5\% remaja pelaku tindak pidana masih mempunyai ayah dan ibu kandungnya dan sekitar 89\% dari mereka tinggal bersama kedua orang tua kandungnya.

Lembaga Center for Public Mental Health (CPMH) melakukan studi awal mengenai psikososial remaja di Propinsi Jawa Tengah dan Jawa Timur, dikarenakan tingginya angka kenakalan remaja disana. Menurut Data Biro Statistik UGM Yogyakarta, pada 2010 sebanyak 14,166 remaja di Propinsi Jawa Tengah dan 2,820 remaja di Jawa Timur berada di rumah tahanan. melibatkan sejumlah 1.200 pelajar SMU di wilayah tersebut dengan rentang waktu Desember 2010 - Februari 2011. PMI mendapat kesimpulan lebih dari $65 \%$ remaja memiliki masalah di keluarga seperti masalah keuangan, masalah percerian orang tua dan kurangnya keharmonisan keluarga. akan berdampak pada banyaknya permasalahan yang timbul, seperti penyalahgunaan alkohol, obat-obatan, ketidak setaraan gender, diskriminasi dan pengucilan, kekerasan terhadap norma - norma budaya, kemiskinan dan kesenjangan akses ekonomi, lemah atau tidak adanya sistem pendukung, dan toleransi terhadap penyalahgunaan kekuasaan.

Data dari pihak Kasat Lantas Padang Pariaman Iptu Yuliadi,SH.MH mengatakan di Padang Pariaman banyak terjadi kenakalan remaja seperti ugal - ugalan mengendarai sepeda motor, mabuk dalam mengendarai sepeda motor, menggunakan NAPZA dan melakukan balapan liar dijalan raya. Kebanyakan dari remaja sekarang hampir $65 \%$ tidak taat pada peraturan lalu lintas. 


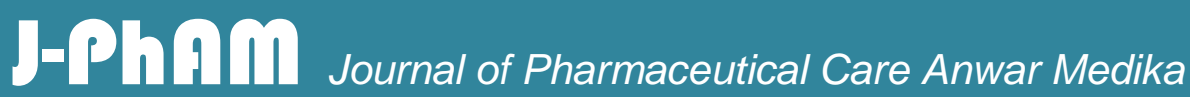

\section{Artikel Penelitian}

Menurutnya banyak remaja salah dalam pergaulan karna itu peran orang tua sangat diharapkan dalam meningkatkan pemahaman aturan kepada anak-anaknya. Berdasarkan hasil survey jumlah siswa kelas I dan II di SMPN 2 Lubuk Alung sebanyak 268 siswa dari 10 lokal yang terdiri 5 lokal kelas I dan 5 lokal kelas II.

Hasil penelitian yang dilakukan oleh Marseliana (2010) tentang hubungan Komunikasi Keluarga dengan perkembangan sosialisasi anak di Bekasi, ditemukan bahwa persentase komunikasi yang fungsional sebesar 66\%, sedangkan komunikasi yang disfungsional sebanyak 34\%, sosialisasi anak dengan tingkat kurang sebanyak $24,5 \%$ dan sedang 75,5\%. Berdasarkan hasil diketahui bahwa anak memiliki tingkat sosialisasi sedang, dari uji statistik chi square didapatkan nilai $\mathrm{p}=0,000(\mathrm{p}<0,005)$ yang berarti terdapat hubungan yang bermakna antara pola komunikasi keluarga dengan perkembangan sosialisasi anak di Bekasi.

Survey awal yang dilakukan di SMPN 2 Lubuk Alung melalui wawancara dengan siswa 8 dari 10 siswa mengaku perokok, sering bolos sekolah, sering berkeliaran dimalam hari dan pernah mengkonsumsi minuman keras. Menurut mereka itu disebabkan kurangnya perhatian dan pengawasan dari orang tua. Laporan dari guru BK juga diketahui banyak siswa yang suka cabut saat jam pembelajaran, tertangkap merokok dilingkungan sekolah, ada juga yang pernah mengancam akan menampar guru dan sering terjadinya perkelahian antara siswa di sekolah tersebut.

\section{BAHAN DAN METODE PENELITIAN}

Jenis penelitian ini adalah deskriptif analitik menggunakan desain cross sectional study, yaitu Variabel Independen dan Variabel Dependen diambil pada saat yang sama untuk melihat hubungan tingkat pengetahuan dan komunikasi keluarga dengan interaksi sosial remaja SMPN 2 Lubuk Alung, Kabupaten Padang Pariaman. Tempat Penelitian adalah di SMPN 2 Lubuk Alung, Kabupaten Padang Pariaman. Penelitian ini dilakukan pada bulan Mei tahun 2019. Teknik pengolahan data yaitu : dengan editing, coding, entry, cleaning dan tabulating. 


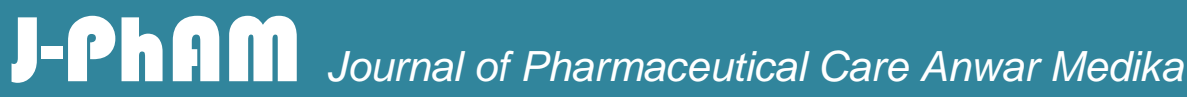

Artikel Penelitian

\section{HASIL PENELITIAN}

Hasil penelitian tentang hubungan tingkat pengetahuan dan komunikasi keluarga dengan interaksi sosialremaja di SMPN 2 Lubuk Alung dengan uraian sebagai berikut:

Tabel 1: Distribusi Frekuensi Interaksi Sosial Remaja Di SMPN 2 Lubuk Alung

\begin{tabular}{ccc}
\hline Interaksi Sosial & $\mathbf{f}$ & $\mathbf{\%}$ \\
\hline Baik & 35 & 47,9 \\
\hline Kurang & 38 & 52,1 \\
\hline Jumlah & 73 & 100 \\
\hline
\end{tabular}

Berdasarkan tabel 1 diatas didapatkan bahwa 35 orang (47,9\%) remaja memiliki interaksi sosial yang baik dan 38 orang $(52,1 \%)$ remaja memiliki interaksi sosial yang kurang baik di SMPN 2 Lubuk Alung.

Tabel 2: Distribusi Frekuensi Pengetahuan Remaja Tentang Interaksi Sosial Remaja Di SMPN 2 Lubuk Alung

\begin{tabular}{ccc}
\hline Pengetahuan Remaja & $\mathbf{f}$ & $\mathbf{\%}$ \\
\hline Tinggi & 33 & 45,2 \\
\hline Rendah & 40 & 54,8 \\
\hline Jumlah & 73 & 100
\end{tabular}

Berdasarkan tabel 2 diatas didapatkan bahwa sebagian besar yaitu $40(54,8 \%)$ orang remaja berpengetahuan yang rendah dan $33(45,2 \%)$ orang remaja berpengetahuan tinggi tentang interaksi sosial di SMPN 2 Lubuk Alung. 
Artikel Penelitian

Tabel 3: Distribusi Frekuensi Komunikasi Keluarga Tentang Interaksi Sosial Remaja Di SMPN 2 Lubuk Alung

\begin{tabular}{ccc}
\hline Komunikasi Keluarga & $\mathbf{f}$ & $\boldsymbol{\%}$ \\
\hline Baik & 36 & 49,3 \\
\hline Kurang Baik & 37 & 50,7 \\
\hline Jumlah & 73 & 100
\end{tabular}

Berdasarkan tabel 3 diatas didapatkan bahwa lebih dari separuh yaitu 37 orang remaja memiliki komunikasi keluarga yang kurang baik tentang interaksi sosial di SMPN 2 Lubuk Alung.

Tabel 5: Hubungan Komunikasi Keluarga Dengan Interaksi Sosial Remaja Di SMPN 2 Lubuk Alung

\begin{tabular}{|c|c|c|c|c|c|c|c|c|}
\hline \multirow{3}{*}{$\begin{array}{c}\text { Komunikasi } \\
\text { Keluarga }\end{array}$} & \multicolumn{4}{|c|}{ Interaksi Sosial } & \multirow{2}{*}{\multicolumn{2}{|c|}{ Total }} & \multirow[b]{2}{*}{ pValue } & \multirow[b]{2}{*}{ OR } \\
\hline & \multicolumn{2}{|c|}{ Baik } & \multicolumn{2}{|c|}{$\begin{array}{c}\text { Kurang } \\
\text { Baik }\end{array}$} & & & & \\
\hline & $\mathbf{F}$ & $\%$ & $\mathbf{f}$ & $\%$ & $\mathbf{F}$ & $\%$ & & \\
\hline Baik & 34 & 94,4 & 2 & 5,6 & 36 & 100 & & \\
\hline Kurang & 1 & 2,7 & 36 & 97,3 & 37 & 100 & 0,000 & 612,0 \\
\hline Total & 35 & 47,9 & 38 & 52,1 & 73 & 100 & & \\
\hline
\end{tabular}

Tabel 5 menunjukkan bahwa remaja yang memiliki interaksi sosial yang kurang baik paling banyak terjadi pada remaja yang mempunyai komunikasi keluarga yang kurang baik yaitu 97,3\% dibandingkan dengan remaja yang mempunyai komunikasi keluarga yang baik yaitu 5,6\%. Hasil uji statistic (chi square) diperoleh nilai $\mathrm{p}=0,000$, maka dapat disimpulkan bahwa terdapat hubungan yang bermakna antara komunikasi keluarga dengan interaksi sosial di SMPN 2 Lubuk Alung. 


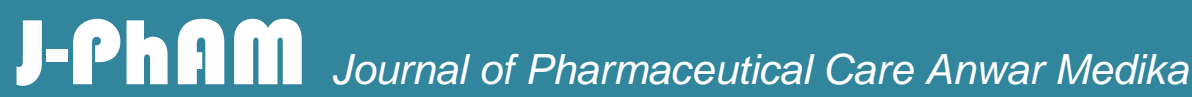

\section{Artikel Penelitian}

\section{PEMBAHASAN}

\section{Interaksi Sosial}

Berdasarkan tabel 1 didapatkan 35 orang $(47,9 \%)$ remaja memiliki interaksi sosial yang baik dan 38 orang $(52,1 \%)$ remaja memiliki interaksi sosial yang kurang baik di SMPN 2 Lubuk Alung. Hasil ini sejalan dengan hasil penelitian yang dilakukan oleh Marseliana (2010) tentang hubungan Komunikasi Keluarga dengan perkembangan sosialisasi anak di Bekasi, ditemukan bahwa persentase sosialisasi anak dengan tingkat kurang sebanyak $24,5 \%$ dan sedang $75,5 \%$.

Interaksi sosial adalah hubungan antar sesama manusia dalam suatu lingkungan masyarakat yang menciptakan status sosial/ hubungan sosial dinamis yang menyangkut hubungan orang - perorangan antar kelompok - kelompok manusia. Teori lain juga disampaikan oleh Soekanto (2013) bahwa interaksi sosial juga dapat dinamakan proses sosial, karna interaksi sosial merupakan syarat utama terjadi aktivitas sosial. Tanpa interaksi sosial tak akan mungkin ada kehidupan bersama, bertemunya orang perorang secara badaniah belaka tidak akan menghasilkan pergaulan hidup dalam suatu kelompok sosial. Pergaulan hidup akan terjadi apabila orang atau kelompok manusia bekerja sama, saling bicara, dan seterusnya untuk mencapai suatu tujuan bersama, mengadakan persaingan, pertikaian dan sebagainya. Maka dapat dikatakan bahwa interaksi sosial adalah dasar proses sosial, pengertian mana menunjukkan pada hubungan sosial yang dinamis. Interaksi sosial kurang baik yang ditunjukkan oleh siswa di SMPN 2 Kecamatan Lembah

Melintang menunjukkan kepribadian yang kurang baik oleh siswa tersebut. Hal ini dapat disebabkan oleh beberapa faktor, sebagaimana yang disampaikan oleh Fatimah (2008) yang menyatakan bahwa kepribadian remaja dipengaruhi oleh faktor internal, terutama citra diri, rasa percaya diri dan faktor eksternal terutama lingkungan sosial yaitu kondisi keluarga, sikap mendidik orang tua, pergaulan dan bentuk interaksi anggota keluarga yang sangat berpengaruh terhadap perkembangan pribadi, citra diri yang sehat, dan adanya rasa percaya diri pada remaja. 


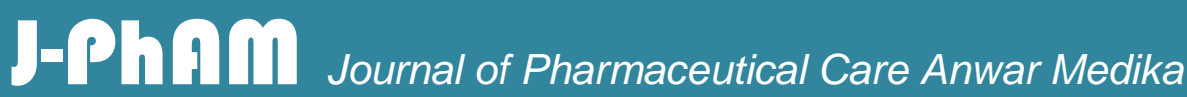

\section{Artikel Penelitian}

Berdasarkan hasil kuesioner didapatkan data bahwa 41,7\% siswa menyatakan bahwa dalam kehidupan sehari - hari mereka lebih suka berdiam diri di rumah dari pada bergaul dengan teman - teman dilingkungan sekitar rumahnya. Padahal menurut sari (2010) bahwa ada dua tingkat interaksi sosial remaja yaitu tingkat interaksi sosial baik dan tingkat interaksi sosial kurang. Tingkat interaksi sosial anak dapat dikatakan baik apabila anak dapat menjalin hubungan yang baik dengan teman - temannya. Tingkat interaksi sosial anak dapat dikatakan kurang apabila anak kurang bisa menjalin suatu hubungan yang baik dengan teman - temannya. Anak lebih banyak diam, lebih suka menyendiri daripada bermain dengan teman - temannya.

Berdasarkan hal ini maka menurut asumsi peneliti adalah interaksi sosial kurang baik pada remaja ditunjukkan oleh kurang bisanya remaja tersebut menjalin hubungan yang baik dengan teman - temannya. Dimana remaja lebih banyak diam, lebih suka menyendiri daripada bermain dengan teman - temannya. Hal ini dapat disebabkan oleh faktor internal dan faktor eksternal remaja tersebut.

\section{Komunikasi Keluarga}

Berdasarkan tabel 3 didapatkan bahwa lebih dari separuh yaitu 37 orang remaja memiliki komunikasi keluarga yang kurang baik di SMPN 2 Lubuk Alung. Hasil ini sejalan dengan hasil penelitian yang dilakukan oleh Marseliana (2010) tentang hubungan Komunikasi Keluarga dengan perkembangan sosialisasi anak di Bekasi, ditemukan bahwa persentase komunikasi yang fungsional sebesar 66\%, sedangkan komunikasi yang disfungsional sebanyak 34\%, sosialisasi anak dengan tingkat kurang sebanyak $24,5 \%$ dan sedang $75,5 \%$.

Galvin dan Brommel (2009) mendefinisikan komunikasi keluarga sebagai proses simbolik transaksional yang terjadi dalam keluarga dalam rangka menciptakan dan memberi makna. Sedangkan Satir (2010) mendefinisikan komunikasi keluarga adalah cara anggota keluarga melakukan berbagai hal untuk membuat arti atau makna terhadap satu sama lain dalam keluarga tersebut. 


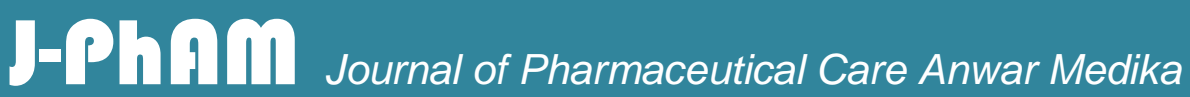

\section{Artikel Penelitian}

Terdapatnya komunikasi keluarga yang kurang baik menggambarkan terjadinya komunikasi disfungsional dalam keluarga. Hal ini dapat disebabkan oleh beberapa faktor yaitu menurut teori Bahri (2010) bahwa faktor - faktor penyebab terjadinya komunikasi disfungsional dalam keluarga yaitu ; 1) Pemusatan pada diri sendiri, yakni seseorang hanya harus pada kebutuhan sendiri untuk mengesampingkan kebutuhan, perasaan orang lain. 2) Nilai dan persetujuan total yakni nilai keluarga yang merupakan upaya untuk memelihara persetujuan total karena adanya perbedaan. Karena dari perbedaan adanya pasangan yang bisa membahagiakan seseorang / individu, dan 3) kurangnya rasa empati.

Berdasarkan hasil kuesioner didapatkan data bahwa 47,6\% menyatakan "tidak" atas pernyataan "Dalam berkomunikasi orang tua saya selalu menganggap saya sebagai partner (teman) sehingga saya lebih santai untuk menyampaikan masalah - masalah saya dalam kehidupan sehari - hari”. Padahal menurut Bahari (2010) bahwa keinginan anak untuk berbicara dengan orang tua dari hati ke hati melahirkan komunikasi interpersonal. Komunikasi disini dilandasi oleh kepercayaan anak kepada orang tua, maka anak akan berusaha membangun keyakinan untuk membuka diri bahwa orang tuanya dapat dipercaya dan sangat mengerti perasaanya. Menjadi pendengar yang baik dan membuka diri untuk berdialog dengan anak adalah langkah awal dalam rangka mengakrabkan hubungan antara orang tua dan anak.

Berdasarkan kondisi ini maka menurut asumsi peneliti terhadap penelitian ini adalah terdapatnya komunikasi keluarga yang kurang baik ada penelitian ini adalah salah satunya tergambar dari kurangnya keterbukaan antara orang tua dengan anak sehingga anak tidak bisa berkomunikasi dengan santai. Oleh sebab itu perlu adanya penguatan terhadap orang tua untuk menciptakan komunikasi terbuka dengan anak pada usia remaja dan melibatkan anak sebagai partner sehingga anak bisa berkomunikasi dengan lebih santai dan terbuka.

\section{Hubungan Pengetahuan Dengan Interaksi Sosial}

Tabel 4 menunjukkan bahwa remaja yang memiliki interaksi sosial yang kurang baik lebih banyak terjadi pada remaja yang berpengetahuan rendah yaitu 80,0\% dibandingkan dengan remaja yang berpengetahuan tinggi yaitu 18,2\% . 


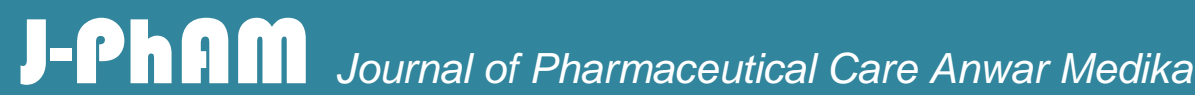

\section{Artikel Penelitian}

Hasil uji statistic (chi square) diperoleh nilai $\mathrm{p}=0,000$, maka dapat disimpulkan bahwa terdapat hubungan yang bermakna antara pengetahuan dengan interaksi sosial di SMPN 2 Lubuk Alung. Nilai OR didapatkan 18,0 artinya peluang terjadinya interaksi social yang kurang baik 18,0 kali terjadi pada remaja yang memiliki pengetahuan rendah.

Adanya hubungan antara pengetahuan dengan interaksi sosial dapat dijelaskan dengan teori Suparyanto (2013) bahwa pengetahuan atau kognitif merupakan domain yang sangat penting untuk terbentuknya tindakan seseorang (overt behavior). Perilaku yang didasari oleh pengetahuan akan lebih langgeng dari pada perilaku yang tidak didasari oleh pengetahuan. Lebih lanjut dikatakan bahwa apabila penerimaan perilaku baru didasari oleh pengetahuan, kesadaran dan sikap positif maka perilaku tersebut akan bersifat langgeng (long lasting), sebaliknya bila tidak didasari pengetahuan dan kesadaran tidak akan bertahan lama.

Begitu juga halnya dengan interaksi sosial pada remaja, jika remaja mempunyai pengetahuan yang tinggi tentang interaksi sosial maka remaja akan dapat melakukan interaksi sosial dengan baik. Sebaliknya jika pengetahuan remaja rendah tentang interaksi sosial maka remaja tidak dapat melakukan interaksi sosial dengan baik. Oleh sebab itu agar interaksi sosial bisa berjalan dengan baik maka perlu adanya peningkatan pengetahuan remaja tentang interaksi sosial. Hal ini dapat dilakukan melalui pemberian informasi kepada remaja tentang interaksi sosial meliputi pengertian, tujuan, interaksi sosial yang baik dan dampak melakukan interaksi sosial yang baik atau kurang baik.

Hasil analisa peneliti semakin baik interaksi social remaja sangat dipengaruhi oleh pengetahuan remaja. Apabila pengetahuan remaja rendah maka interaksi sosial remaja menjadi kurang baik. Dengan demikian perlu adanya kerjasama antara pihak sekolah dengan pihak yang memahami psikologi remaja untuk melakukan upaya pemberian informasi tentang interaksi sosial pada remaja. Upaya ini bisa dilakukan melalui seminar remaja, melalui majalah dinding penyuluhan ataupun melalui cara lain yang menarik bagi remaja di SMPN 2 Lubuk Alung. 


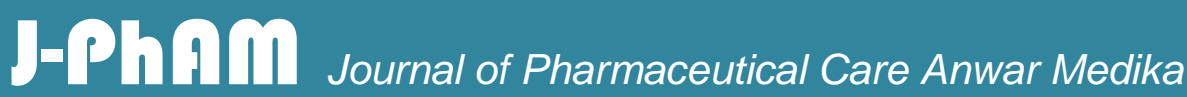

\section{Artikel Penelitian}

\section{Hubungan Komunikasi Keluarga Dengan Interaksi Sosial}

Tabel 5. menunjukkan bahwa remaja yang memiliki interaksi sosial yang kurang baik paling banyak terjadi pada remaja yang mempunyai komunikasi keluarga yang kurang baik yaitu 97,3\% dibandingkan dengan remaja yang mempunyai komunikasi keluarga yang baik yaitu 5,6\%. Hasil uji statistic (chi square) diperoleh nilai $\mathrm{p}=0,000$, maka dapat disimpulkan bahwa terdapat hubungan yang bermakna antara komunikasi keluarga dengan interaksi sosial di SMPN 2 Lubuk Alung. Nilai OR didapatkan 612,0 artinya peluang terjadinya interaksi social yang kurang baik 612,0 kali terjadi pada remaja yang memiliki komunikasi kurang baik.

Hasil ini sejalan dengan hasil penelitian yang dilakukan oleh Marseliana (2010) tentang hubungan Komunikasi Keluarga dengan perkembangan sosialisasi anak di Bekasi, ditemukan bahwa dari uji statistik chi squaredidapatkan nilai $\mathrm{p}=0,000(\mathrm{p}<0,005)$ yang berarti terdapat hubungan yang bermakna antara pola komunikasi keluarga dengan perkembangan sosialisasi anak di Bekasi.

Hubungan antara komunikasi keluarga dengan interaksi sosial remaja dapat dijelaskan dengan teori Bahari (2010) bahwa komunikasi keluarga sebagai salah satu cara untuk menyelesaikan persoalan yang ada. Jika dalam keluarga terdapat komunikasi yang efektif, terbuka dan ada umpan balik di antara orang tua dan anak maka segala permasalahan akan dapat dipecahkan bersama karena adanya keterdekatan dan kepercayaan antara orang tua dan anak. Dan sebaiknya orang tua harus memperhatikan, mendidik dan meluangkan waktu untuk anaknya sehingga anak tidak akan salah dalam memilih teman dan akan terjalin keluarga yang harmonis.

Berdasarkan hal ini maka menurut asumsi peneliti adalah agar interaksi sosial remaja menjadi baik maka komunikasi keluarga juga harus diperbaiki. Karena dengan adanya komunikasi keluarga yang baik maka anak akan lebih terbuka terhadap masalah sehingga bissa dibantu oleh anggota keluarga dalam penyelesaian masalah remaja sehingga remaja dapat melakukan interaksi sosial dengan baik. 


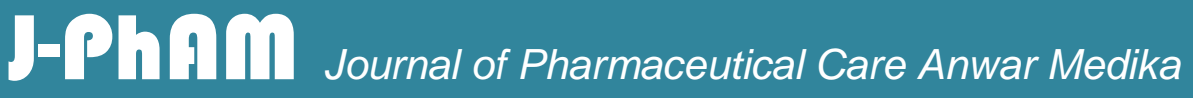

Artikel Penelitian

\section{KESIMPULAN DAN SARAN}

Berdasarkan hasil penelitian yang telah dilakukan tentang hubungan tingkat pengetahuan dan komunikasi keluarga dengan interaksi sosial pada remaja kelas I dan II di SMPN 2 Lubuk Alung tahun 2019, dapat disimpulkan bahwa terdapat hubungan yang bermakna antara pengetahuan dengan interaksi sosial di SMPN 2 Lubuk Alung ( $p=0,000)$ dan terdapat hubungan yang bermakna antara komunikasi keluarga dengan interaksi sosial di SMPN 2 Lubuk Alung ( 


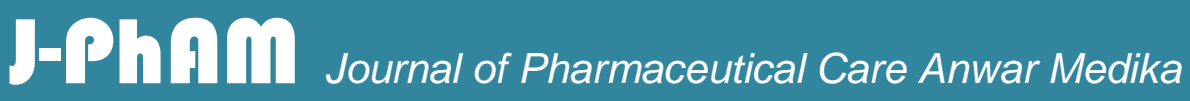

Artikel Penelitian

\section{DAFTAR PUSTAKA}

1. Al-Mighwar M. Psikologi remaja. Bandung: Pustaka Setia; 2010

2. Kozier B, Glenora ERB, Audrey B, Shirlee J. Fundamental keperawatan: konsep, proses dan praktik. Edisi-7. Jakarta: EGC; 2010

3. Santrock JW. Remaja. Edisi-11. Jakarta: Gelora Aksara Pratama; 2009

4. Fatimah E. Psikologi perkembangan: perkembangan peserta didik. Bandung: Pustaka Setia; 2010

5. Bahri Djamarah S. Pola komunikasi orang tua dan anak dalam keluarga. Jakarta: Rineka Cipta; 2009

6. Walgito B. Pengantar psikologi umum. Yogyakarta: Andi; 2009

7. Esqil. Cara membangun komunikasi yang baik dengan anak.1 Maret 2013. Dari http://m.muslimahzone.com/cara-membangun-komunikasi-yang-baik-dengan-anak/. Diakses 05 maret 2019

8. Paulis. Kenakalan remaja. 4 Desember 2012. Diambil dari http://paulisfsgm.blogspot.com/2012/12/kenakalan-remaja.html. Di akses Maret 2019

9. Soekanto S. Sosiologi suatu pengantar. Jakarta: Raja Grafindo Persada; 1990 Didib. Diambil dari http://www.slideshare.net/ihsannurthefallen/kelompok-5-faktor-faktor-yangmempengaruhi-interaksi-sosial. Diakses 8 Maret 2019

10. Sofa. Perilaku sosial. 24 juli 2011. Diambil dari http://massofa.wordpress.com/2011/07/24/perilaku-sosial/. Diakses 8 Maret 2019

11. Notoatmodjo S. Promosi kesehatan reori dan aplikasinya. Jakarta: Rineka Cipta; 2015

12. Suparyanto. Sekilas tentang pengetahuan. Diambil dari http://caraun.blogspot.com/2012/11/sekilas-tentang-pengetahuan.html. Diakses 7 Maret 2019

13. Nasir A, Muhith A, Sajidin M, Iqbal Mmubarok W. Komunikasi dalam keperawatan: teori dan aplikasi. Jakarta: Salemba Medika; 2011 